Original Article

\title{
ESTIMATION OF RESIDUAL SOLVENTS IN NETUPITANT API BY HEADSPACE GAS CHROMATOGRAPHY
}

\author{
SUNNY GRACE GODE ${ }^{1}$, VIJAYA LAKSHMI G. ${ }^{2 *}$ \\ ${ }^{1}$ Department of Pharmacy, University College of Technology, Osmania University, Hyderabad, Telangana State India, ${ }^{2}$ Department of \\ Chemistry, Osmania University College for Women, Koti 500095, Hyderabad, Telangana State India \\ Email: gvjlakshmi@gmail.com
}

Received: 29 Jul 2021, Revised and Accepted: 09 Sep 2021

\begin{abstract}
Objective: Residual solvents are undesirable components present in Active Pharmaceutical Ingredients (API), excipients, or drug products. To meet the specific quality-based requirements, the presence of these solvents in pharmaceutical products should be monitored to ensure their safety. The main objective of this work is to develop a new method for the determination of residual solvents in netupitant API by an HS-GC method with an FID detector.

Methods: An automated headspace GC method has been developed and validated for the estimation of the residual solvents- $\mathrm{N}$-methyl pyrrolidine, xylene, toluene, and N, N Dimethylacetamide in netupitant API. The samples were dissolved in dimethyl sulfoxide and the equilibrium headspace gas was formed at $80^{\circ} \mathrm{C}$, which was analyzed using a DB-624 column $\left(30 \mathrm{~m}^{*} 0.53 \mathrm{~mm}, 3.00 \mu \mathrm{m}\right)$ with an injector and detector temperature set at $160^{\circ} \mathrm{C}$ and $230{ }^{\circ} \mathrm{C}$, respectively. The initial oven temperature was set at $60^{\circ} \mathrm{C}$ for $5 \mathrm{~min}$ and programmed at a rate of $10{ }^{\circ} \mathrm{C} / \mathrm{min}$ to the final temperature of $150^{\circ} \mathrm{C}$, with a hold time of $5 \mathrm{~min}$ by maintaining the flow rate of $4.0 \mathrm{ml} / \mathrm{min}$ with a split ratio of $1: 10$, and total run time of 20 min. Nitrogen was used as carrier gas. The method developed was validated as per International Conference for Harmonization (ICH) guidelines for repeatability, linearity, range, ruggedness, detection limit, quantification limit, and recovery studies.
\end{abstract}

Results: The linearity range selected was $50-350 \mu \mathrm{g} / \mathrm{ml}$ and the correlation coefficient $\left(\gamma^{2}\right)$ values for all the solvents were found to be>0.99; recovery studies values were in a range of $90-110 \%$ and \%RSD values were also found to be not more than 10 for the solvents.

Conclusion: A novel, accurate, sensitive, and simple method was described for estimating residual solvents in Netupitant API by Headspace Gas Chromatography (HS-GC) coupled with a Flame Ionization Detector (FID). Excellent results have been observed for all the validated parameters with good peak resolution and lesser retention times.

Keywords: Netupitant, Residual solvents, Headspace gas chromatography, International conference on harmonization

(C) 2021 The Authors. Published by Innovare Academic Sciences Pvt Ltd. This is an open access article under the CC BY license (https://creativecommons.org/licenses/by/4.0/) DOI: https://dx.doi.org/10.22159/ijpps.2021v13i11.42781. Journal homepage: https://innovareacademics.in/journals/index.php/ijpps.

\section{INTRODUCTION}

Residual solvents are organic volatile impurities that are used or formed in different processes of synthesis or manufacture of pharmaceutical drug substances, intermediates, excipients, or drug products [1]. These solvents are toxic, possess no therapeutic importance, and may affect the quality and stability of the drug substances and drug products, because of which their presence is highly not acceptable in the final product. The selection of solvent for enhancing the yield of drug substance or for determining the characteristics like crystal form, solubility, and purity may sometimes be a crucial parameter in the synthesis process [2]. Even after subjecting too many common techniques like increased process temperature or decreasing pressure that are used in general manufacturing processes, they are completely not removed [3, 4]. ICH guideline Q3C(R6) recommends the use of less toxic solvents and acceptable amounts for residual solvents in pharmaceuticals for the safety of the patient and also, the amount of solvent present should be evaluated and justified [5]. The term "permitted daily exposure" (PDE) was defined in this guideline as a pharmaceutically acceptable intake of residual solvents [5]. After evaluation, if the calculated values are equal to or below the recommended/acceptable level, no testing for the residual solvents in the drug product is needed and is safe for human use; and if the calculated values are above the recommended/acceptable level, then the drug product should undergo testing for ensuring the safety of that particular drug for human use [5].

The most commonly used method for estimation of residual solvents is static HS-GC with FID detector in pharmaceuticals. The reasons why this method is preferred for validation over other analytical techniques are, (i) its fully automated, (ii) sample preparation is easy, (iii) high separation efficiency, and (iv)sensitivity for volatile organic solvent [6, 7]. All these advantages for HS-GC have made it the most important tool in determining and quantifying the residual solvents.
In general, $25 \%$ to $30 \%$ of patients with a diagnosis of cancer receive chemotherapy as treatment. Out of these, $70 \%-80 \%$ experience one of the most distressing side effects, nausea, and vomiting which has an immense impact on the quality of life of patients receiving certain antineoplastic therapies [8]. Netupitant is a potential antiemetic drug that acts as a selective neurokinin1 (NK 1) receptor antagonist. It competitively binds to and also blocks the activity of human substance P/NK 1 receptors in the central nervous system (CNS), then inhibiting NK-1 receptor binding of endogenous tachykinin neuropeptide substance $\mathrm{P}(\mathrm{SP})$, which thereby results in the prevention of chemotherapy-induced nausea and vomiting (CINV) [8]. This drug was approved in October 2014 by FDA for use in combination with palonosetron for the prevention of acute and delayed vomiting and nausea associated with cancer chemotherapy, including highly emetogenic chemotherapy [9].

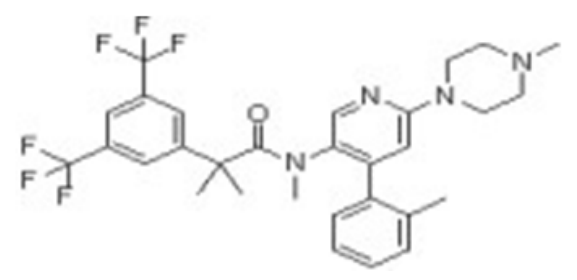

Fig. 1: Structure of netupitant [10]

From the scheme of synthesis for Netupitant [8], residual solventstoluene, xylene, $\mathrm{N}, \mathrm{N}$-dimethylacetamide, and $\mathrm{N}$-methyl pyrrolidine were used in the synthesis and purification process of the drug. 
These solvents in the drug product are needed to be validated and quantified to ensure their safety for human use. The present study mainly focuses on the novel method development and validation for the estimation of residual solvents in Netupitant API by the HS-GC method with FID detection.

\section{MATERIALS AND METHODS}

\section{Materials}

All the chemicals used were of GC Grade. N-methyl pyrrolidine and N, N-dimethylacetamide were obtained from Qualigens, Mumbai. Xylene, toluene, and dimethyl sulfoxide were obtained from Sigma Aldrich, Bengaluru. Netupitant API was a gift sample obtained from Chandra Labs, Hyderabad.

\section{Instrument details}

Work was studied on Agilent Infinity 7697A Head Space Gas Chromatography with flame ionization detector and the software used was Open labs EZChrome Software. For weighing, Mettler Toledo precision balance was used.

\section{Method development}

The headspace GC method has been developed stepwise systematically [11]. In the first trial, DB-620 $\left(80 \mathrm{~m}^{*} 0.22 \mathrm{~mm}, 1.8 \mu \mathrm{m}\right)$ column was taken, where injection temperature and the detector temperature were set to $180{ }^{\circ} \mathrm{C}$ and $230{ }^{\circ} \mathrm{C}$ respectively with an initial oven temperature $80{ }^{\circ} \mathrm{C}$ and programmed at the rate of 10 ${ }^{\circ} \mathrm{C} / \mathrm{min}$ to the final temperature of $180{ }^{\circ} \mathrm{C}$ with a flow rate of 2.0 $\mathrm{ml} / \mathrm{min}$. Headspace equilibrium temperature was taken as $80{ }^{\circ} \mathrm{C}$ with a run time of $35 \mathrm{~min}$. The merging of peaks $\mathrm{N}$-methyl acetamide and xylene have been observed. Hence optimization of the method is required for good separation of peaks.

For the next trial, DB-624(50m*0.22 mm,1.8 $\mu \mathrm{m})$ column was taken, where injection temperature and detector temperature were set to $160{ }^{\circ} \mathrm{C}$ and $230{ }^{\circ} \mathrm{C}$ respectively with the initial temperature of $70{ }^{\circ} \mathrm{C}$ and programmed at the rate of $10^{\circ} \mathrm{C} / \mathrm{min}$ to the final temperature of $150{ }^{\circ} \mathrm{C}$ with flow rate $3.0 \mathrm{ml} / \mathrm{min}$. Headspace equilibrium temperature was $80{ }^{\circ} \mathrm{C}$ with a total run time $30 \mathrm{~min}$. In this trial, separation was achieved, but a poor resolution was observed. Hence, further optimization was required to fulfill a good resolution.

In the final trial, DB-624(30m*0.53, $3.0 \mu \mathrm{m})$ was taken, where injection temperature and detector temperature were set to $160^{\circ} \mathrm{C}$ and $230{ }^{\circ} \mathrm{C}$ respectively with the initial temperature of $60{ }^{\circ} \mathrm{C}$ and programmed at the rate of $10^{\circ} \mathrm{C} / \mathrm{min}$ to the final temperature of 150 ${ }^{\circ} \mathrm{C}$ with flow rate $4.0 \mathrm{ml} / \mathrm{min}$. Headspace equilibrium temperature was $80^{\circ} \mathrm{C}$ with a total run time $20 \mathrm{~min}$. The separation of peaks with a good resolution has been observed in this trial.

\section{Optimization details}

Column selection is a very crucial parameter for achieving good separation in GC analysis. For getting effective results, some columns were investigated. For the first and second columns, the response was found to be unsatisfactory with poor resolution. More optimization was required, which was fulfilled by the third column. This column has shown good peak resolution with lesser retention time. Therefore, DB-624(30m*0.53 mm, $1.8 \mu \mathrm{m})$ was selected for carrying out this study. The selection of temperature is also one of the important factors in achieving good resolution as the utmost care has to be taken that the analyte is not degraded in the complete analysis [12]. The injection temperature was changed from $180^{\circ} \mathrm{C}$ to $160{ }^{\circ} \mathrm{C}$ and the oven initial and final temperatures have fluctuated from $60{ }^{\circ} \mathrm{C}-80{ }^{\circ} \mathrm{C}$ and $150{ }^{\circ} \mathrm{C}-150{ }^{\circ} \mathrm{C}$, respectively. Control of flow rate also determines the resolution of peaks. The flow rate was varied from $2.0 \mathrm{ml} / \mathrm{min}-4.0 \mathrm{ml} / \mathrm{min}$ to get a good resolution of peaks. Because of making few deliberate changes in these parameters, good resolution of peaks with lesser retention times has been observed. The optimized chromatographic conditions were inlet temperature was $160^{\circ} \mathrm{C}$ and detector temperature was $230^{\circ} \mathrm{C}$. The column used was DB-624 $(30 \mathrm{~m} \times 0.53 \mathrm{~mm}, 3.0 \mu \mathrm{m})$ column. The initial oven temperature was kept at $60^{\circ} \mathrm{C}$ for $5 \mathrm{~min}$ and the final oven temperature was $150{ }^{\circ} \mathrm{C}$, increasing @ $10{ }^{\circ} \mathrm{C} / \mathrm{min}$ withhold time $5 \mathrm{~min}$. The flow rate was $4.0 \mathrm{ml} / \mathrm{min}$ with a split ratio of 1:10.
The carrier gas used was nitrogen. Headspace optimized conditions for oven temperature, transfer line temperature, and loop fill temperature were found to be $80^{\circ} \mathrm{C}, 90^{\circ} \mathrm{C}$, and $100^{\circ} \mathrm{C}$, respectively. The total run time was 20 min.

\section{Procedure}

These studies were carried out at $25^{\circ} \mathrm{C}$. The solubility of Netupitant was found to be more in dimethyl sulfoxide; hence it is used as diluent.

\section{Preparation of blank solution}

Transferred $1.0 \mathrm{ml}$ of diluent in headspace vial and sealed the vial immediately.

\section{Preparation of standard solution}

Weighed accurately $500 \mathrm{mg}$ of xylene, $500 \mathrm{mg}$ of toluene, $500 \mathrm{mg}$ of $\mathrm{N}, \mathrm{N}$-dimethylacetamide, and $500 \mathrm{mg}$ of $\mathrm{N}$-methyl pyrrolidine in 200 $\mathrm{ml}$ volumetric flask containing about $80 \mathrm{ml}$ of diluent and then made up the volume with diluent and shaken well.

\section{Preparation of working standard solution}

From the standard solution, $10 \mathrm{ml}$ was pipetted out into a $200 \mathrm{ml}$ volumetric flask containing about $20 \mathrm{ml}$ diluent. Made up the volume with diluent. Pipetted out $1 \mathrm{ml}$ of the above-prepared solution in the headspace vial and sealed the vial immediately.

\section{Preparation of test solution}

Weighed accurately $500 \mathrm{mg}$ of the test sample (Netupitant API) and transferred it to a $50 \mathrm{ml}$ volumetric flask containing $35 \mathrm{ml}$ diluent, vortexed it for $5 \mathrm{~min}$. Then the volume was made up with the diluent and mixed well. Pipetted out $1.0 \mathrm{ml}$ of the above-prepared solution in the headspace vial and sealed the vial immediately.

\section{Experimental}

Transferred the above-prepared solutions into headspace vials, sealed immediately and injected into the system; and used as per the procedures mentioned in ICH guidelines for validating the parameter for evaluating the residual solvents. To avoid excessive peak broadening, adequate flow should be maintained throughout the system.

\section{RESULTS}

In this study, the HS-GC method has been developed and validated for the quantitative determination of residual solvents xylene, toluene, N, N-dimethylacetamide, and N-methyl pyrrolidine in Netupitant API. The validation was done as per ICH guidelines by using standard addition with internal standard quantitation for the estimation of four residual solvents. Specificity (by direct comparison method), detection and quantification limits, linearity and repeatability, recovery $(75 \%, 100 \%$ and $150 \%)$, robustness (changing oven temperature), and ruggedness (analyst change) were determined. The results obtained were excellent. The method validated has shown good reproducibility, recovery, and linearity; justified the preparation of standard in dimethyl sulfoxide with high resolution and lesser retention time.

\section{Specificity}

Specificity is determined by the direct comparison method. DB$624(30 \mathrm{~m} \times 0.53 \mathrm{~mm}, 3 \mu \mathrm{m})$ column has been selected because it has a standard stationary phase as recommended by different pharmacopeias. It has been observed that diluent or API peaks are not interfering at the retention times of the solvent peaks i.e.; xylene, toluene, N, N-dimethylacetamide, and N-methyl Pyrrolidine and have shown excellent peak resolution, which resulted in good column efficiency (fig. 2 and 3). Hence the method was found specific.

\section{System suitability, method precision, and repeatability}

The procedure was carried out as mentioned in ICH guidelines for determining the system suitability and method precision. Six independent determinations were carried out, by individually weighing the amounts of the solvents, and \%RSD values were calculated. For repeatability studies, the same procedure was followed by different analysts, and \%RSD was calculated. Acceptance criteria were \%RSD should be not more than $10 \%$ and observed 
values for each solvent were found to be less than $10 \%$. This indicates that the proposed method passed system suitability testing and has shown good reproducibility and repeatability (table 1 ). The result indicates the method was capable with high precision. And also, good separations were achieved, which suggests that the method was selective for all components under the test.

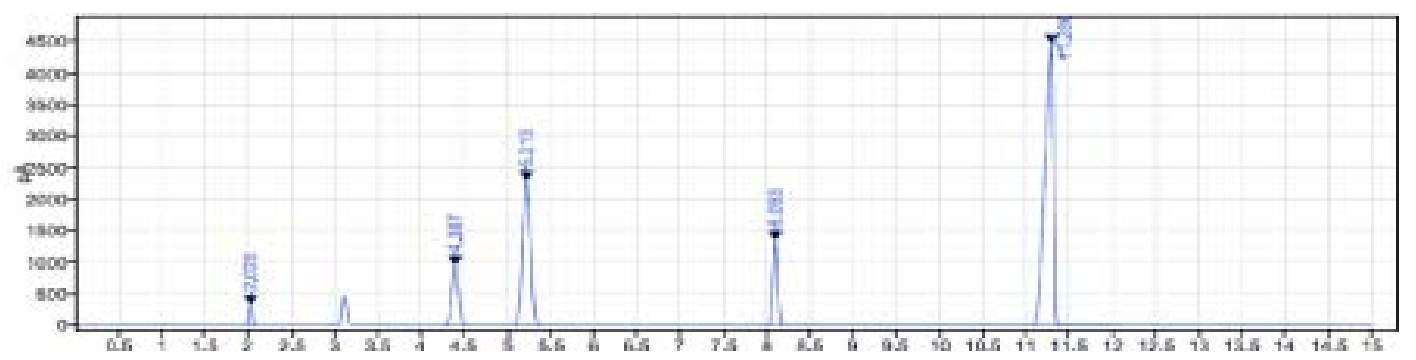

Fig. 2: Chromatogram for the specificity of standards

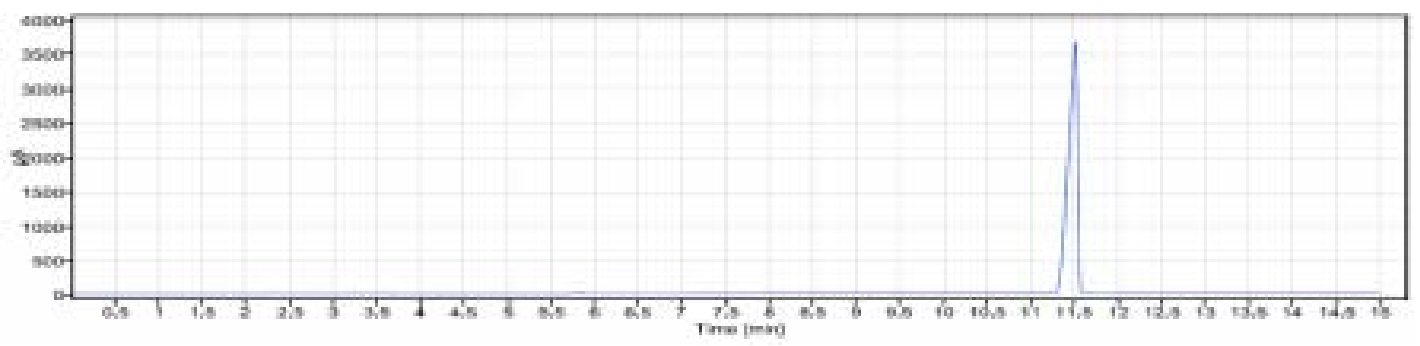

Fig. 3: Chromatogram for the specificity of blank

Table 1: Method precision and intermediate precision data

\begin{tabular}{lllll}
\hline Solvent & \multicolumn{5}{l}{ Method precision intermediate precision } & & \%RSD \\
\cline { 2 - 5 } & mean \pm SEM & \%RSD & $1034.98 \pm 4.74$ & 1.12 \\
N-Methyl Pyrrolidine & $1090.24 \pm 20.93$ & 4.70 & $4804.00 \pm 40.59$ & 2.08 \\
N, N- Dimethyl Acetamide & $5119.24 \pm 68.67$ & 3.29 & $12739.6 \pm 291.33$ & 5.93 \\
Xylene & $15642.12 \pm 341.55$ & 5.35 & $4746.62 \pm 31.04$ & 1.60 \\
Toluene & $5080.73 \pm 44.11$ & 2.13 & & \\
\hline
\end{tabular}

$*$ mean \pm SEM denotes the reliability of data at $95 \%$ confidence interval with z-value 1.960 , SEM is the standard error of mean which is calculated by, $\sigma /(\mathrm{n})^{1 / 2}$; where $\sigma$ is the standard deviation for the residual solvents and $\mathrm{n}$, a number of injections=6; and RSD is the relative standard deviation.

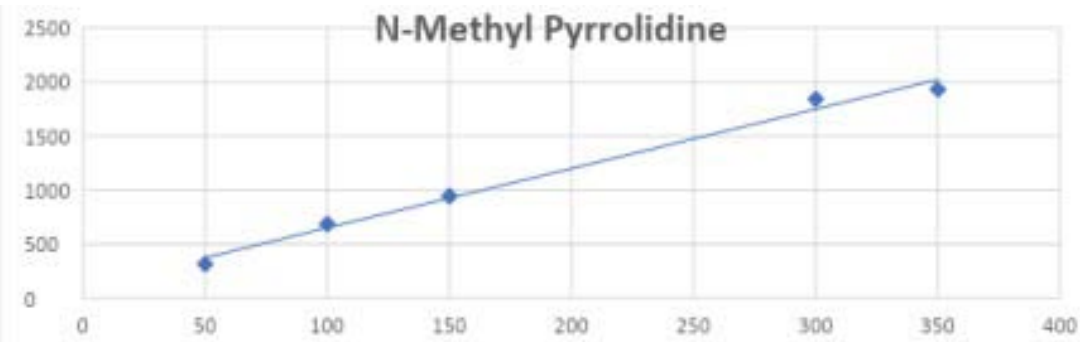

Fig. 4: Linearity curve for N-methyl pyrrolidine

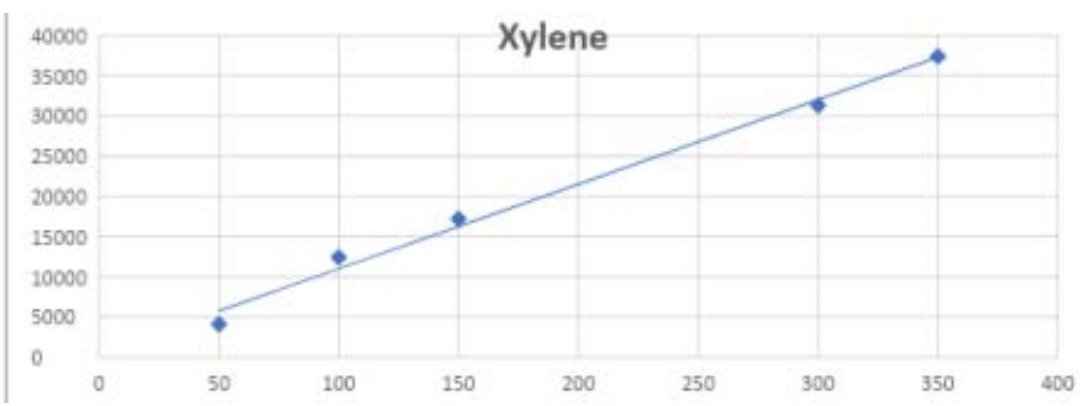

Fig. 5: Linearity curve for xylene 


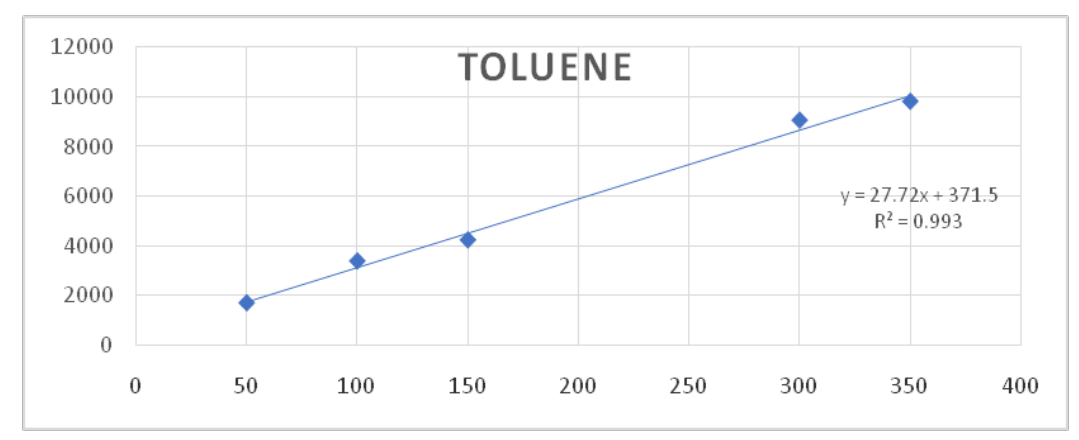

Fig. 6: Linearity curve for toluene

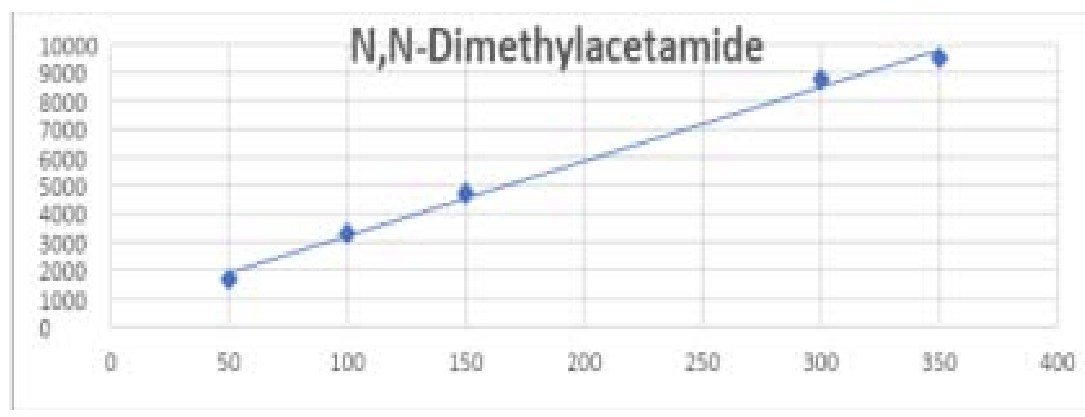

Fig. 7: Linearity curve for $\mathrm{N}, \mathrm{N}$-dimethylacetamide

\section{Linearity studies}

This study was carried out by taking five different standard solutions ranging from $50 \mu \mathrm{g} / \mathrm{ml}$ to $350 \mu \mathrm{g} / \mathrm{ml}$ that were prepared for each solvent. The results obtained were represented in a calibration curve and a statistical study was carried out. This relationship of concentrations with responses of each solvent should be linear within the specified range with a correlation coefficient not less than 0.99 . It was observed that this method was linear within a wider range for all the solvents which are in the validation. The correlation coefficient for each solvent was found to be>0.99 and also linear regression has shown a positive response throughout the range (table 2). The range is normally derived from linearity studies.

\section{Detection and quantification limits}

Detection limit and quantification limit values were calculated as those concentrations that gave $\mathrm{S} / \mathrm{N}$ ratio 3 and $\geq 10$ respectively and give low residual linearity values. Six independent determinations were carried out for determining the limit of detection (LOD) and limit of quantification (LOQ) values by diluting the standard solution and spiked on the diluent and injected into HS-GC (table 2).

Table 2: Residual solvents validation results

\begin{tabular}{lllll}
\hline Solvent & Specificity RT (mins) & Linearity $\boldsymbol{\gamma}^{\mathbf{2}}$ & $\mathbf{L O D}(\boldsymbol{\mu g} / \mathbf{m l})$ & LOQ $(\boldsymbol{\mu g} / \mathbf{m l})$ \\
\hline N-Methyl Pyrrolidine & 2.02 & 0.990 & 30.83 & 93.44 \\
N,N-Dimethyl acetamide & 4.39 & 0.995 & 21.07 & 63.83 \\
Xylene & 5.22 & 0.992 & 26.26 & 79.58 \\
Toluene & 8.10 & 0.993 & 12.86 & 38.97 \\
\hline
\end{tabular}

${ }^{*}$ RT denotes retention time in minutes, $\gamma^{2}$ denotes correlation coefficient, LOD and LOQ are limits of detection and quantification respectively measured in $\mu \mathrm{g} / \mathrm{ml}$.

Table 3: System suitability under robustness

\begin{tabular}{lllllllll}
\hline Conditions & \multicolumn{2}{l}{ N-methyl pyrrolidine } & \multicolumn{2}{l}{ N, N-dimethyl acetamide } & Xylene & \multicolumn{2}{l}{ Toluene } \\
\cline { 2 - 8 } & mean \pm SEM & \%RSD & mean \pm SEM & \%RSD & mean \pm SEM & \%RSD & mean \pm SEM & \%RSD \\
\hline Control & $1090.24 \pm 20.93$ & 4.70 & $5119.24 \pm 68.67$ & 3.29 & $15642.12 \pm 341.55$ & 5.35 & $5080.73 \pm 44.11$ & 2.13 \\
High oven temperature & $10777.6 \pm 5.14$ & 0.83 & $4927.64 \pm 40.62$ & 1.43 & $13710.71 \pm 330.24$ & 4.28 & $4987.7 \pm 26.79$ & 0.93 \\
Low oven temperature & $633.47 \pm 11.82$ & 3.13 & $2749.61 \pm 68.53$ & 4.16 & $7489.7 \pm 305.5$ & 6.74 & $2557.56 \pm 58.9$ & 3.85 \\
\hline
\end{tabular}

*mean \pm SEM values at $95 \%$ confidence interval with $\mathrm{z}$-Value 1.960 for all the residual solvents where $\mathrm{n}$, number of injections=3 is calculated and RSD is relative standard deviation value.

\section{Robustness}

Robustness was performed by changing the oven temperature for which the \%RSD values observed were not more than 10 and within the acceptance criteria (table 3). Hence the method was found to be robust with concern to changes made deliberately.

\section{Accuracy (Recovery studies)}

The accuracy of the method was determined by the standard addition method at 3 levels. To the API at the quantitation limit (QL) the solvents were added at the level of $75 \%, 100 \%$, and $150 \%$. The recovery studies were carried out in triplicate and percentage recovery and percentage 
mean recovery were calculated for the drug and solvents. All the values were found to be between $90-110 \%$ which is very much in acceptance within the prescribed limits i.e.; \% recovery should be within $80-120 \%$ according to the ICH guidelines (table 4).

Table 4: Recovery studies or accuracy data

\begin{tabular}{llll}
\hline $\begin{array}{l}\text { Spiking level } \\
\text { (\% of QL) }\end{array}$ & $\begin{array}{l}\text { N-Methyl pyrrolidine } \\
\text { (\%recovery) }\end{array}$ & $\begin{array}{l}\text { N, N-Dimethyl acetamide } \\
\text { (\%recovery) }\end{array}$ & Toluene (\%recovery) \\
\hline $75 \%$ & 93.08 & 90.17 & 117.02 \\
$100 \%$ & 96.56 & 98.02 & 105.63 \\
$150 \%$ & 103.89 & 107.06 & 107.97 \\
\hline
\end{tabular}

${ }^{*} \mathrm{QL}$ denotes quantification limit at the spiked level

Table 5: Summary of validation parameters for the method developed

\begin{tabular}{ll}
\hline Specificity & Diluent or API peaks are not interfering with the retention times of solvent peaks \\
\hline Linearity & $\gamma^{2} \geq 0.99$ \\
Method Precision(\%RSD) & $2.13-4.70$ \\
Intermediate Precision(\%RSD) & $1.12-5.93$ \\
Accuracy (\% Recovery) & $90.17-117.02$ \\
Detection Limit & $12.86-30.84$ \\
Quantification Limit & $38.97-93.44$ \\
Ruggedness & \%RSD for all the solvents were within the acceptance limits \\
Robustness & \%RSD for all the solvent peak areas and content in $\mu \mathrm{g} / \mathrm{ml}$ is within the acceptance limits \\
\hline
\end{tabular}

\section{DISCUSSION}

In this study, a novel chromatographic method has been developed and validated for the estimation of residual solvents in Netupitant API. Few analytical methods have been reported for the estimation of Netupitant $[9,13]$. However, the HS-GC method has not been reported earlier for Netupitant API.

Method development for optimizing the chromatographic conditions has been a very crucial step. Trails were done and the optimized method was found to be feasible and easily adaptable. Compared to other analytical methods, HS-GC generally takes a longer time to complete the analysis $[4,6,7,11,12]$. In contrast, this method's GC run time was 20 min which indicates that the estimation of residual solvents in Netupitant API can be carried out rapidly and efficiently.

The retention times for the $\mathrm{N}$-methyl pyrrolidine, $\mathrm{N}, \mathrm{N}$-Dimethyl acetamide, xylene, and toluene were 2.02, 4.39, 5.22, and 8.10 respectively. Compared to other GC methods for these solvents, the retention times observed in this method were less $[4,6,7,11,12,15$, 16]. There was no interference of dissolving solvent peak at the retention times to that of solvent peaks. Fig. 2 and 3 show all peaks well resolved, hence the method was found to be specific.

Tables 1 and 3 show all \%RSD values not more than 10\% for precision, intermediate precision, and system suitability testing. The data was reported in mean \pm SEM values which signifies the reliability of the results. From tables 4 and 5, the percentage recovery for each solvent at $75 \%, 100 \%$ and, $150 \%$ was found to be in the range of 90 $120 \%$ which is very much in acceptance with ICH specified limits. From the above-obtained results, it was proved that the developed method is more accurate and precise.

The linear relationship was evaluated across the range of concentration of analyte solvents $(50 \mu \mathrm{g} / \mathrm{ml}-350 \mu \mathrm{g} / \mathrm{ml})$ and calculated correlation coefficient values were found to be $\gamma^{2}>0.99$ (fig. 4-7 and Tables 2 and 5). LOD and LOQ values for each solvent were found to be satisfactory (table 2 and 5). By introducing deliberate changes in the system, made no or very negligible difference as the RSD values remained $<10 \%$ for all the solvents (table 3 and 5). All the obtained results for the validation parameters met the ICH accepted criteria. In comparison to other reported HSGC methods [4-7, 11, 12, 14-16], this method was found to be more specific, reliable and, accurate. Hence, it can be effectively applied for routine analysis in research institutions.

\section{CONCLUSION}

By observing the results and summarized validation parameters, it was concluded that the newly developed method for the estimation of residual solvents N-Methyl Pyrrolidine, N, N-Dimethyl Acetamide, xylene, and toluene in Netupitant API was found to be accurate, simple, precise, with high resolution and lesser retention time which makes this method very much acceptable and economical. It can be effectively applied in quality control departments in industries, approved testing laboratories, bio-pharmaceutical, and bioequivalence studies, and also in pharmacokinetic studies in near future.

\section{ACKNOWLEDGEMENT}

The author would like to express sincere gratitude to the Council for Scientific and Industrial Research (CSIR), New Delhi for providing financial assistance and University College of Technology, Osmania University, Hyderabad.

\section{AUTHORS CONTRIBUTIONS}

G Sunny Grace: Performed the experiments on method development and validation, analyzed data, and drafted the manuscript.

G Vijaya Lakshmi: Thoroughly reviewed and revised the manuscript.

\section{CONFLICT OF INTERESTS}

\section{Declared none}

\section{REFERENCES}

1. Singh Prashant K, Singh Lokesh K, Pande Milind, Tripathi Ram B. Steps to be considered during method development and validation for analysis of residual solvents by gas chromatography. Int Res J Pharm App Sci. 2013;3:74-80.

2. Grotowski Katarzyna, Barczewski Andrzej. Analytical methods for residual solvents determination in pharmaceutical products. Acta Pol Pharm Drug Res. 2010;67:13-26.

3. Medley Colin D, Kay Jacob, Li Y, Gruenhagen Jason, Yehl Peter, Chetwyn Nik P. Quantification of residual solvents in antibody drug conjugates using gas chromatography. Anal Chim Acta. 2014;850:92-6. doi: 10.1016/j.aca.2014.09.003. PMID 25441165.

4. Ahmad Shoeb Al, Amer Almardini Mohd, Yahia Mahzia. Validated HS-GC-FID method for determination of residual ethanol in a solid dosage form. Res J Pharm Technol. 2014;7:184-7.

5. Naddaf A, Balla J. Comparison of quantitative analytical methods in HS GC of residual solvents. Springer; 2000. p. S241-8.

6. Sojitra Chandrakant, Tehare Ajay, Dholakia Chintan, Sudhakar Padmaja, Agarwal Sameer, Singh Kumar K. Development and validation of residual solvent determination by headspace gas chromatography in imatinib mesylate API. SN Appl Sci. 2019;1(3):233-9. doi: 10.1007/s42452-019-0233-x.

7. Sai Kiran B, Nayudamma Chowdary Y, Sree Lakshmi V, Shrivastava SK, Pugazhendhi S. Development and validation of head pace gas 
chromatographic method for determination of residual solvents in bosentan monohydrate. Siva Int J PharmTech Res. 2014;2:421-7.

8. Dr. Crasto Anthony Melvin. New drug approvals: Fosnetupitant EU; 2015.

9. Panigrahy Uttam Prasad, Sunil A, Reddy Kumar. A novel validated RP-HPLC-DAD method for simultaneous estimation of netupitant and palonosetron in bulk and pharmaceutical dosage form with forced degradation studies. Int J ChemTech Res. 2015;8:317-37.

10. Structure of netupitant: Adooq Biosciences. Available from: https://www.biogenuix.com. [Last accessed on 15 Jun 2021]

11. Kishore J, Rao PK. Development and validation of a gas chromatography headspace method for the simultaneous quantification of six volatile impurities in sumatriptan succinate API and its pharmaceutical dosage forms. Asian J Pharm Clin Res. 2020;13:210-8.

12. Mishra G, Saxena V, Jawla S, Srivastava VK. Method development and validation for the determination of residual solvents in omeprazole API by using headspace gas chromatography. Asian J Pharm Clin Res. 2013;7:54-6.

13. Dr. Kumar Gampa Vijay, Sravanthi B, Gayathri Aparna N. Development and validation of RP-HPLC method for simultaneous estimation of netupitant and palonosetron in the pharmaceutical dosage form. Indo Am J Pharm Sci. 2018;5:16746-55.

14. Jahnavi N, Saravanan VS. Method development and validation for the determination of residual solvents in methocarbamol pure drug by HS-GC. IJ Res Pharm Chem. 2012;2:456-67.

15. Rele RV, Mali RN. Determination of residual solvents in citalopram hypo bromide by gas chromatography. Am J PharmTech Res. 2012;2:619-25.

16. Ramos CS. Development and validation of a headspace chromatographic method for determination of residual solvents in five drug substances. Int J Pharm Sci Invent. 2013;2:36-41. 